\title{
The Maternal ITPK1 Gene Polymorphism Is Associated with Neural Tube Defects in a High-Risk Chinese Population
}

\author{
Zhen Guan $^{19}$, Jianhua Wang ${ }^{19}$, Jin Guo ${ }^{1}$, Fang Wang ${ }^{1}$, Xiuwei Wang ${ }^{1}$, Guannan Li ${ }^{1}$, Qiu Xie ${ }^{1}$, Xu Han ${ }^{1}$, \\ Bo Niu ${ }^{1 *}$, Ting Zhang ${ }^{2 *}$
}

1 Department of Biotechnology, Capital Institute of Pediatrics, Beijing, China, 2 Beijing Municipal Key Laboratory of Child Development and Nutriomics, Capital Institute of Pediatrics, Beijing, China

\begin{abstract}
Background: Epidemiological surveys and animal studies have revealed that inositol metabolism is associated with NTDs, but the mechanisms are not clear. Inositol 1,3,4-trisphosphate 5/6-kinase (ITPK1) is a pivotal regulatory enzyme in inositol metabolic pathway. The objective was to assess the potential impact of the maternal ITPK1 genotypes on the inositol parameter and on the NTD risk in a NTD high-risk area in China.

Methodology/Results: A case-control study of pregnant women affected with NTDs $(n=200)$ and controls $(n=320)$ was carried out. 13 tag SNPs of ITPK1 were selected and genotyped by the Sequenom MassArray system. We found that 4 tag SNPs were statistically significant in spina bifida group $(P<0.05)$. MACH was used to impute the un-genotyped SNPs in ITPK1 locus and showed that 3 meaningful SNPs in the non-coding regions were significant. We also predicted the binding capacity of transcription factors in the positive SNPs using the bioinformatics method and found that only rs3783903 was located in the conserved sequence of activator protein-1 (AP-1). To further study the association between biochemical values and genotypes, maternal plasma inositol hexakisphosphate (IP 6 ) levels were also assessed using LC-MS. The maternal plasma $\mathrm{IP}_{6}$ concentrations in the spina bifida subgroup were $7.1 \%$ lower than control (136.67 vs. $\left.147.05 \mathrm{ng} \mathrm{mL}{ }^{-1}, P<0.05\right)$, and significantly lower in rs3783903 GG genotype than others $(P<0.05)$. EMSA showed a different allelic binding capacity of AP-1 in rs3783903, which was affected by an A $\rightarrow$ G exchange. The RT-PCR suggested the ITPK1 expression was decreased significantly in mutant-type of rs3783903 compared with wild-type in the 60 healthy pregnancies $(P<0.05)$.
\end{abstract}

Conclusions/Significance: These results suggested that the maternal rs3783903 of ITPK1 might be associated with spina bifida, and the allele G of rs3783903 might affect the binding of AP-1 and the decrease of maternal plasma IP 6 concentration in this Chinese population.

Citation: Guan Z, Wang J, Guo J, Wang F, Wang X, et al. (2014) The Maternal ITPK1 Gene Polymorphism Is Associated with Neural Tube Defects in a High-Risk Chinese Population. PLOS ONE 9(1): e86145. doi:10.1371/journal.pone.0086145

Editor: Dmitri Zaykin, National Institute of Environmental Health Sciences, United States of America

Received June 17, 2013; Accepted December 5, 2013; Published January 20, 2014

Copyright: (c) 2014 Guan et al. This is an open-access article distributed under the terms of the Creative Commons Attribution License, which permits unrestricted use, distribution, and reproduction in any medium, provided the original author and source are credited.

Funding: This work was supported by the National Natural Science Foundation (81070491). The funders had no role in study design, data collection and analysis, decision to publish, or preparation of the manuscript.

Competing Interests: The authors have declared that no competing interests exist.

* E-mail: niub2004@126.com (BN); zhangtingcv@aliyun.com (TZ)

9 Zhen Guan, Jianhua Wang, contributed equally to this manuscript.

\section{Introduction}

Neural tube defects (NTDs) refer to a group of serious defects and its etiology is multifactorial, involving the genetic and environmental factors [1]. As a maternal nutrition factor, inositol plays a vital role in the development of neural tube. An epidemiological study conducted by Groenen et al showed that serum levels of inositol in NTDs-affected pregnant women were significantly lower than that of healthy pregnant women and pregnant women with lower serum levels of inositol are more susceptible to NTDs by 2.6 fold [2]. In animal studies, inositol can reduce the incidence of spina bifida in the genetic model of folateresistant NTDs [3]. The study from E. Albert Reece et al showed that supplementation of inosotol $(0.08 \mathrm{mg} / \mathrm{d})$ to pregnant mice reduced the incidence of NTDs to the next generations from
$20.4 \%$ to $9.5 \%$ [4]. Recently, myo-inositol soft gelatin capsules are considered as the preventive treatment of NTDs in folate-resistant subjects [5]. In a word, results suggest that as a nutritional substance, inositol is closely related to the development of NTDs.

ITPK 1 is a pivotal regulatory enzyme in the synthesis of inositol tetraphosphate $\left(\mathrm{IP}_{4}\right)$, inositol pentakisphosphate $\left(\mathrm{IP}_{5}\right)$, inositol hexakisphosphate $\left(\mathrm{IP}_{6}\right)$. ITPK 1 catalyzes the inositol 1,3,4-trisphosphate $\left[\mathrm{I}(1,3,4) \mathrm{P}_{3}\right]$ into the $\mathrm{IP}_{4}$ which is further transformed to $\mathrm{IP}_{5}$ by a 5 -kinase and to $\mathrm{IP}_{6}$ by a 2 -kinase[6-8]. These products regulate various cellular processes. $\mathrm{IP}_{4}$ inhibits the permeability of CLC3 channel and participates in the cellular signal transduction pathway; while $\mathrm{IP}_{6}$ is an intracellular signaling molecule, participating in the regulation of ion channels, exocytosis, endocytosis, transcription, DNA synthesis and RNA transport. Silencing or over-expression of ITPK1 gene affected the levels of its 
downstream products, $\mathrm{IP}_{4}, \mathrm{IP}_{5}$ and $\mathrm{IP}_{6}$, resulting in inositol metabolic disorder [9]. The animal experiments demonstrated that ITPK1 was expressed in the highest level in brain and the mice with reduced levels of ITPK 1 developed NTDs [10]. The structure and function changes of ITPK1 induced by polymorphisms might affect the metabolism of salt, fluid and endocrine in cell which lead to the abnormality cell proliferation, differentiation and apoptosis, therefore disrupting the normal development of neural tube. In conclusion, ITPK1 gene might be closely correlated with NTDs.

Previous studies indicated that maternal inositol level played an important role in NTD susceptibility. These researches were focused on animal and cell models and the population studies about the ITPK1 gene were still lack. Weather the different susceptibility is caused by the polymorphism of the key gene ITPK1 has not been reported. For this reason, we genotyped the polymorphism of ITPK1 gene and tested maternal plasma IP $_{6}$ level to assess the potential impact of the maternal ITPK1 genotypes on the inositol parameter and on the NTD risk in the high-risk area of Lvliang, Shanxi Province in China.

\section{Materials and Methods}

\section{Ethics Statement}

The study protocol was reviewed and approved by the Ethics Committees Review Board of Capital Institute of Pediatrics, Beijing, China. We obtained written informed consent from all parents.

\section{Study Population}

We conducted a hospital-based case-control study from 2004 to 2009 in Shanxi Province in Northern China which have an NTD prevalence of 199.38 per 10,000 births [11]. Effective sample sizes (320 controls VS 200 cases) for case-control study were calculated by Quanto 1.1 ver. software and the power was set at $80 \%$ [12]. We chose 200 pregnant women with NTDs diagnosed with Bultrasound examination. The pathological diagnosis of NTDs was completed by experienced pathologists according to the International Classification of Diseases, Tenth Revision, codes Q00 anencephaly, Q05 spina bifida, and Q01 encephalocele (http:// apps.who.int/classifications). As for control group, women who had a live-born infant with no identified structural malformation after 1-year follow-up and who aborted for nonmedical reasons were enrolled from this region. The nonmedical aborted fetus also underwent the pathological anatomy. Any fetuses displaying pathological malformations or intrauterine growth retardation were excluded from the control group. When pregnant women were recruited, their clinical information was collected and recorded. Generally, $2 \mathrm{ml}$ of venous blood was collected and stored at $-20^{\circ} \mathrm{C}$ in local hospitals before shipping, on ice, to the study laboratories. Samples were not thawed until analysis. The population of our study was extragenetic and specifically selected and we have avoided the false positive results caused by population stratification. The collection of the samples was strictly controlled. We only had collected "anencephaly", "spina bifida" and "encephalocele", and there were not any other defects.

To validate the mRNA levels of the different SNPs, we recruited 60 healthy pregnant women (22-24 gestational weeks) from the Beijing Obstetrics and Gynecology Hospital, and collected the $2.5 \mathrm{ml}$ venous blood in a PAXgene Blood RNA Tube (BRT). Immediately after blood collection, the PAXgene ${ }^{\circledR}$ Blood RNA Tube was gently inverted 8-10 times and stored the PAXgene ${ }^{\circledR}$ Blood RNA Tube upright at room temperature $\left(18^{\circ} \mathrm{C}\right.$ to $\left.25^{\circ} \mathrm{C}\right)$ for a minimum of 2 hours. After that, the tube was then transferred to freezer $\left(-20^{\circ} \mathrm{C}\right)$ before shipping, on ice, to the study laboratories.

\section{DNA Extraction}

Genomic DNA was extracted from frozen blood samples using the Blood DNA Kit (Qiagen, Germany) according to the manufacturer's instructions and was subsequently used for genotyping. DNA concentration and purity were determined by absorbance at $260 \mathrm{~nm}$ and $280 \mathrm{~nm}$.

\section{RNA Extraction}

Genomic RNA was extracted from frozen blood samples using PAXgene Blood RNA Kit (Qiagen, Germany) according to the manufacturer's protocol and was subsequently used for RT-PCR. RNA concentration and purity were determined by absorbance at $260 \mathrm{~nm}$ and $280 \mathrm{~nm}$.

\section{Single-Nucleotide Polymorphism Selection}

In our study, tag SNPs were selected from the Haploview software 4.2 (Mark Daly's lab of Broad Institute, Cambridge, MA, Britain) [13] using HapMap Genome Browser release\#24 (Phase $1 \& 2$ - full dataset ) data [14] based on the CHB+JPT population and dbSNPs (http://www.ncbi.nlm.nih.gov/projects/SNP/) databases by the criterion that minor allele frequencies $>0.2$, pairwise correlation $r^{2}>0.8$, giving first priority to those in coding exons, and then those underlying regulatory elements. Combined with the principles of Sequenom genotyping primer design, 13 tag SNPs were finally selected.

\section{Genotyping Approach}

All cases and controls were genotyped for the selected SNPs of the ITPK1 gene were using Sequenom MassARRAY System with matrix-assisted laser desorption/ionization time-of-flight (MALDITOF) mass spectrometry (Sequenom, San Diego, California). Two primers for Polymerase chain reaction (PCR) amplification and one primer for extension primers were designed using RealSNP (https://www.mysequenom.com/). Approximately $20 \mathrm{ng}$ of genomic DNA was used to genotype each sample. The data were analyzed using Type Analysis 4.0. We had done the validation study about the genotyping accuracy in ITPK1 gene. The Sequenom genotyping platform is medium-throughput. In order to ensure the genotyping consistency, $10 \%$ of samples were re-genotyped, and another $10 \%$ of samples were sequenced directly to validate the accuracy of the genotyping. Sequencing results were exported to Mutation Surveyor Version 3.25 (Softgenetics, State College, PA, USA; http://www.softgenetics.com) for alignment and multiple comparisons. Genotyping quality control study contained 1 blank sample, 2 repeated samples, and a $>90 \%$ of genotyping call rate.

\section{Prediction Transcription Factor and Function Tests}

We predicted the binding capacity to potential transcription factor for the different genotypes in the four positive tag SNPs using the bioinformatics method (http://www.gene-regulation. com/pub/programs/alibaba2/index.html) and found the AA genotype of rs3783903 was located in the conserved sequence of approximate transcription factors (AP-1) and there were not any other predicted transcription factor binding sites in the oligo of rs3783903. The other 3 sites were also analyzed and the results showed that they were located in the non-conserved sequences of the transcription factor binding sites. Then we applied EMSA to detect whether the rs3783903 polymorphism could change the binding ability of the sequence to the transcription factor AP-1.

\section{Determination of $\mathrm{IP}_{6}$ in Maternal Plasma}

The plasma concentration of inositol $\left(\mathrm{IP}_{6}\right)$ was detected according to the protocol of the previous study [15]. The $200 \mathrm{ul}$ 
Table 1. The general characteristics of the study subjects.

\begin{tabular}{|c|c|c|c|}
\hline Characteristics & Case $\left(\mathrm{N}=200^{\mathrm{a}}, \%^{\mathrm{b}}\right)$ & Control $\left(\mathrm{N}=320^{\mathrm{a}}, \%\right)$ & $P^{c}$ \\
\hline Age (year) & 194 & 325 & \\
\hline$<20$ & $14(7.2)$ & $25(7.7)$ & 0.112 \\
\hline $20-29$ & $147(75.8)$ & $220(67.7)$ & \\
\hline$>29$ & $33(17)$ & $80(24.6)$ & \\
\hline Educational level & 190 & 301 & \\
\hline$<$ Middle school graduation & $15(7.9)$ & $35(11.6)$ & 0.199 \\
\hline Middle school graduation & $142(74.7)$ & $203(67.4)$ & \\
\hline$>$ Middle school graduation & $33(17.4)$ & $63(20.9)$ & \\
\hline Gravidity (n) & 187 & 302 & \\
\hline 1 & $13(7)$ & $31(10.3)$ & 0.45 \\
\hline 2 & $20(10.7)$ & 33(10.9) & \\
\hline$\geq 3$ & $154(82.3)$ & $238(78.8)$ & \\
\hline Parity (n) & 186 & 299 & \\
\hline 0 & $23(10.22)$ & $30(10.04)$ & 0.316 \\
\hline 1 & $13(7.30)$ & $32(10.78)$ & \\
\hline$\geq 2$ & $150(82.48)$ & $237(79.18)$ & \\
\hline Periconceptional folic acid use & 166 & 280 & \\
\hline No ${ }^{d}$ & $156(93.9)$ & $271(96.8)$ & 0.156 \\
\hline Yes & $10(6.1)$ & $9(3.2)$ & \\
\hline Gestational week & 195 & 304 & \\
\hline$<21$ & $108(55.4)$ & $200(65.8)$ & 0.041 \\
\hline $21-29$ & $58(29.7)$ & $76(25)$ & \\
\hline$\geq 30$ & $29(14.9)$ & $28(9.2)$ & \\
\hline
\end{tabular}

${ }^{\mathrm{a}}$ Referes to the number of subject.

bercentages may not equal 100 because of rounding.

${ }^{\mathrm{C} C h i}$-square test was used to calculate the $p$ values.

dThe "periconceptional" refer to the month before conception and the first 3 months after conception.

doi:10.1371/journal.pone.0086145.t001

plasmas were transferred into the EP tubes; 20 ul of $0.1 \mathrm{M}$ EDTA and $20 \mathrm{ul}$ of $6.1 \mathrm{~N}$ trichloroacetic acid were added into the tubes. Then the mixture was vortexed and centrifuged at $5200 \mathrm{~g}$ for $10 \mathrm{~min}$ at $4^{\circ} \mathrm{C}$. The supernatant $(60 \mathrm{ul})$ was collected and added the $60 \mathrm{ul}$ of $50 \mathrm{mM}$ TEAA buffer, $\mathrm{pH}$ 9. Mixtures were vortexed and taken the $50 \mathrm{ul}$ sample was injected into the LC-MS apparatus (system 1). We selected 60 subjects from spina bifida groups and controls, respectively.

\section{Nuclear Extracts and Electromobility Shift Assay (EMSA)}

Nuclear Extracts from Hela cells were prepared following the instructions and the protocol (NE-PER Nuclear and Cytoplasmic Extraction Reagents). To determine the crucial role of the rs3783903 at the region of the ITPK1 intron, the oligonucleotides containing the nucleotide $\mathrm{A}$ or $\mathrm{G}$ at $\mathrm{rs} 3783903$ was designed. The AP-1 core sequence was $\left(5^{\prime}\right.$-AGTCA- $\left.3^{\prime}\right)$. The sequences for these double-stranded oligonucleotides were: the probes biotinylated at the 5' end (Sangon Biotech (Shanghai) Co, Ltd ), A (5'tgaaagtgcAgtcaagatggtag- $\left.3^{\prime}\right)$ and $\mathrm{G}$ (5'-tgaaagtgcGgtcaagatggtag$\left.3^{\prime}\right)$. The oligonucleotides were incubated for $20 \mathrm{~min}$ with an equal amount of nuclear extracts in the presence of $10 \%$ glycerol, $1 \mathrm{ul}$ dIdC, binding buffer. A 200-fold excess of A or G cold probes non biotinylated at the $5^{\prime}$ end were used in competiton assays. The DNA-protein complexes were run on a $6 \%$ acrylamide gel and transferred to a $\mathrm{N}+$ nylon membrane, cross-linked and revealed by chemiluminescence (Light Shift Chemiluminescent EMSA kit,
Pierce). We used protein-specific supershift antibodies, anti-c-jun (H-79, sc-1694) and anti-c-fos (sc-52) antibodies (Santa Cruz CA, USA), to identify the components of the AP-1 transcription factor in the DNA-protein complex. These antibodies were incubated with the nuclear extracts for $30 \mathrm{~min}$ at room temperature before incubation with those probes. Besides, the unlabeled mutant probe was added to the wild-type labeled probe lane.

\section{Validation of the Differentially Expressed Genotypes by Quantitative Real-time PCR (RT-PCR)}

Total RNA was extracted from the peripheral blood of the healthy women using QIAamp ${ }^{\circledR}$ RNA Blood Mini Handbook Kit(QIAamp ${ }^{\circledR}$ ). Real-time qPCR analysis was performed at CWBio.Co. Ltd. (Beijing, China). Briefly, the NEB E. coli poly (A) polymerase was firstly used to add poly (A) tail to total RNA. Complementary DNA was synthesized by using the SuperRT Two Step RT-PCR Kit reverse transcriptase (CWbio.Co, Ltd) and mRNA specific reverse transcription primers. SYBR Green (UltraSYBR Mixture, CWbio.Co Ltd) uptake in double-stranded DNA was measured using ABI 7500 Sequence Detection System in the presence of SYBR-Green. We calculated ITPK1 (Forward: ACGGCTCGAAGTCGTATGAG Reverse: GGGAAAGTCAAGCGGTTCTTC) and used this statistic to determine relative gene expression. Glyceraldehyde-3-phosphate dehydrogenase (GAPDH) was used as an internal control gene (Forward: 
Table 2. The positive tag SNPs genotypes and allele frequencies in NTDs and controls.

\begin{tabular}{|c|c|c|c|c|c|c|}
\hline SNP & Genotype/Allele & Cases (\%) & Controls (\%) & $P^{\mathrm{a}}$ & $O R$ & OR(95\%Cl) \\
\hline \multirow[t]{6}{*}{ rs4586354 } & $\pi$ & $81(47.4)$ & $164(54.1)$ & & 1 & \\
\hline & $\mathrm{CT}$ & $70(40.9)$ & $123(40.6)$ & 0.48 & 1.15 & {$[0.77,1.71]$} \\
\hline & $\mathrm{CC}$ & $20(11.7)$ & $16(5.3)$ & 0.009 & 2.53 & {$[1.25,5.10]$} \\
\hline & $\mathrm{CT}+\mathrm{CC}$ & $90(52.6)$ & 139 (45.9) & 0.15 & 1.31 & {$[0.90,1.91]$} \\
\hline & $\mathrm{T}$ & $232(67.8)$ & 451 (74.4) & & 1 & \\
\hline & $C$ & $110(32.2)$ & 155 (25.6) & 0.03 & 1.38 & {$[1.03,1.85]$} \\
\hline \multirow[t]{6}{*}{ rs3783903 } & AA & $74(40.9)$ & $165(52.2)$ & & 1 & \\
\hline & AG & $87(48.1)$ & $136(43)$ & 0.07 & 1.43 & {$[0.97,2.09]$} \\
\hline & GG & $20(11)$ & $15(4.7)$ & 0.002 & 2.97 & {$[1.44,6.13]$} \\
\hline & $A G+G G$ & $107(57.5)$ & $151(47.8)$ & 0.015 & 1.58 & {$[1.09,2.28]$} \\
\hline & A & $235(64.9)$ & $466(73.7)$ & & 1 & \\
\hline & G & $127(35.1)$ & $166(26.3)$ & 0.003 & 1.52 & {$[1.10,2.00]$} \\
\hline \multirow[t]{6}{*}{ rs2236131 } & GG & $78(44.3)$ & $181(58)$ & & 1 & \\
\hline & AG & $79(44.9)$ & $115(36.9)$ & 0.019 & 1.59 & {$[1.08,2.35]$} \\
\hline & AA & $19(10.8)$ & $16(5.1)$ & 0.004 & 2.76 & {$[1.35,5.64]$} \\
\hline & $A G+A A$ & $98(55.7)$ & $138(42.3)$ & 0.008 & 1.65 & {$[1.13,2.4]$} \\
\hline & G & $235(66.8)$ & 477 (76.4) & & 1 & \\
\hline & A & $117(33.2)$ & 147 (23.6) & 0.001 & 1.62 & {$[1.20,2.15]$} \\
\hline \multirow[t]{6}{*}{ rs1740689 } & $A A$ & 55 (31.6) & $139(44.3)$ & & 1 & \\
\hline & AG & $88(50.6)$ & $143(45.5)$ & 0.043 & 1.55 & {$[1.03,2.30]$} \\
\hline & GG & $31(17.8)$ & $32(10.2)$ & 0.002 & 2.45 & {$[1.36,4.40]$} \\
\hline & $\mathrm{AG}+\mathrm{GG}$ & $119(68.4)$ & $175(55.8)$ & 0.006 & 1.7 & {$[1.16,2.54]$} \\
\hline & A & $198(56.9)$ & $421(67)$ & & 1 & \\
\hline & G & $150(43.1)$ & 207 (33) & 0.002 & 1.54 & {$[1.17,2.02]$} \\
\hline
\end{tabular}

Abbreviations: NTD, neural tube defect; SNP, single-nucleotide polymorphism; $O R$, odds ratio; $C l$, confidence interval.

${ }^{a}$ The $P$ value remained significant after Bonferroni correction at 0.05 levels.

doi:10.1371/journal.pone.0086145.t002

\section{ATGGGGAAGGTGAAGGTGG; Reverse: GGGGTCATT- GATGGCAACAATA).}

\section{Statistical Analysis}

The genotype frequency of SNP was tested for Hardy-Weinberg equilibrium (HWE) in cases and controls by the Chi-square test. The indicator of linkage disequilibrium (LD), $r^{2}$ (square of correlation coefficient), and the haplotype frequencies were analyzed using online SNPstats software at http://bioinfo. iconcologia.net/SNPstats [16]. General characteristics of the participants were presented as the mean and standard deviations (SDs) for continuous measures, while frequencies and percentages were used for categorical measures. Association of genetic polymorphisms of ITPK1 gene with NTD risk was analyzed using univariate analysis through Chi-square test and Fisher's exact test. The correlation between each SNP and NTDs risk was estimated by logistic regression analysis with adjustment for other variables. MACH $[17,18]$ was used to impute the un-genotyped SNPs in ITPK1 locus, using the reference panel ASN data (1000 Genomes Integrated Phase 1). Association test was performed by using logistic regression. The statistical analysis was conducted using SPSS statistical analysis software, version 17.0 (SPSS, Chicago, IL, USA). Association was expressed as odds ratios (OR) with 95\% confidence intervals $(C I)$. The association was considered to be significant when the $P$-value was $<0.05$.

\section{Results}

\section{General Characteristics of the Participants}

We recruited 200 cases and 320 matched controls and conducted a hospital-based case-control study in the Lvliang mountain area of Shanxi Province in northern China and preliminarily investigated the association between ITPK1 gene and NTDs. There were 101 anencephaly cases, 80 spina bifida cases and 19 encephalocele cases. The average genotyping call rate was $>90 \%$ in all samples. Re-genotyping results showed a $100 \%$ concordance. The general characteristics of the participants are shown in Table 1. There was no significant difference between groups in maternal age, mother's educational level, gravidity, parity and periconceptional folic acid use. The gestational week of controls was lower than that of cases.

\section{Association of Genetic Polymorphisms of ITPK1 Gene with NTDs Risk}

The 13 tag SNPs of ITPK1 gene were genotyped and all polymorphisms were in Hardy-Weinberg equilibrium. The study showed that the four tag SNPs were significantly different between cases and controls (Table S1). While anencepahly and spina bifida might be considered as primary neurulation defects, and encephaloceles as post-neurulation defects, we removed the encephaloceles from the analysis. Meanwhile, anencepahly and spina bifida were separately analyzed in subtypes. We re-analyzed 
Table 3. The results of imputation and association test for the SNPs in ITPK1 locus.

\begin{tabular}{|c|c|c|c|c|c|c|c|c|}
\hline SNP & Position & Allele & MAF in Cases & MAF in Controls & $O R$ & Standard Error & $P$-value & Type \\
\hline rs882023 & 93532014 & $\mathrm{~T} / \mathrm{C}$ & 0.429 & 0.3258 & 1.82 & 0.16 & $1.59 \mathrm{E}-04$ & int $u s 2 k^{a}$ \\
\hline rs10132322 & 93487943 & $\mathrm{G} / \mathrm{A}$ & 0.3657 & 0.2776 & 1.93 & 0.18 & $2.52 \mathrm{E}-04$ & int $\operatorname{trp}^{b}$ \\
\hline rs8013870 & 93518403 & $A / G$ & 0.4311 & 0.3701 & 1.35 & 0.15 & $3.86 \mathrm{E}-02$ & int trp \\
\hline rs55948122 & 93484627 & $\mathrm{~T} / \mathrm{C}$ & 0.312 & 0.2045 & 3.48 & 0.23 & $3.25 \mathrm{E}-08$ & int \\
\hline rs3783902 & 93482450 & $A / G$ & 0.3323 & 0.2209 & 3.26 & 0.22 & 4.37E-08 & int \\
\hline rs56857003 & 93482868 & $\mathrm{G} / \mathrm{C}$ & 0.3346 & 0.2239 & 3.26 & 0.23 & $4.70 \mathrm{E}-08$ & int \\
\hline rs3783904 & 93482298 & $\mathrm{G} / \mathrm{A}$ & 0.3325 & 0.2255 & 3.29 & 0.23 & $7.00 \mathrm{E}-08$ & int \\
\hline rs12433984 & 93482709 & $\mathrm{G} / \mathrm{A}$ & 0.3369 & 0.2277 & 3.19 & 0.22 & 7.36E-08 & int \\
\hline rs3783905 & 93482211 & $\mathrm{C} / \mathrm{T}$ & 0.3304 & 0.2239 & 3.26 & 0.23 & $8.22 \mathrm{E}-08$ & int \\
\hline rs55919031 & 93452687 & $\mathrm{C} / \mathrm{T}$ & 0.3068 & 0.2184 & 2.71 & 0.23 & $6.43 \mathrm{E}-06$ & int \\
\hline rs7154944 & 93450468 & $\mathrm{~T} / \mathrm{G}$ & 0.3105 & 0.2233 & 2.65 & 0.23 & $9.28 \mathrm{E}-06$ & int \\
\hline rs4905020 & 93447573 & $\mathrm{~A} / \mathrm{C}$ & 0.3092 & 0.222 & 2.63 & 0.22 & $1.00 \mathrm{E}-05$ & int \\
\hline rs1815226 & 93439195 & $C / A$ & 0.3074 & 0.2197 & 2.58 & 0.22 & $1.18 \mathrm{E}-05$ & int \\
\hline rs3783915 & 93446992 & $\mathrm{C} / \mathrm{T}$ & 0.3098 & 0.2234 & 2.58 & 0.22 & $1.36 \mathrm{E}-05$ & int \\
\hline rs3783916 & 93441153 & $\mathrm{C} / \mathrm{T}$ & 0.3098 & 0.2234 & 2.56 & 0.22 & 1.47E-05 & int \\
\hline rs55652648 & 93445141 & $\mathrm{G} / \mathrm{A}$ & 0.3099 & 0.2237 & 2.56 & 0.22 & $1.49 \mathrm{E}-05$ & int \\
\hline rs3783918 & 93439911 & $A / G$ & 0.3095 & 0.2231 & 2.55 & 0.22 & $1.55 \mathrm{E}-05$ & int \\
\hline rs4905016 & 93438765 & $C / G$ & 0.309 & 0.2226 & 2.47 & 0.22 & $2.15 \mathrm{E}-05$ & int \\
\hline rs12589194 & 93438410 & $\mathrm{~T} / \mathrm{C}$ & 0.3073 & 0.22 & 2.44 & 0.21 & $2.23 \mathrm{E}-05$ & int \\
\hline rs3783919 & 93437614 & $A / G$ & 0.3071 & 0.2199 & 2.43 & 0.21 & $2.30 \mathrm{E}-05$ & int \\
\hline rs3825684 & 93437581 & $C / G$ & 0.3073 & 0.2197 & 2.42 & 0.21 & $2.32 \mathrm{E}-05$ & int \\
\hline rs67182772 & 93437363 & $\mathrm{~T} / \mathrm{C}$ & 0.3068 & 0.2195 & 2.41 & 0.21 & $2.49 \mathrm{E}-05$ & int \\
\hline rs61446566 & 93436493 & $\mathrm{C} / \mathrm{T}$ & 0.3064 & 0.219 & 2.4 & 0.21 & $2.56 \mathrm{E}-05$ & int \\
\hline rs58809802 & 93550093 & $A / G$ & 0.2913 & 0.2047 & 2.4 & 0.21 & $2.74 \mathrm{E}-05$ & int \\
\hline rs57854715 & 93432730 & $\mathrm{~T} / \mathrm{A}$ & 0.3021 & 0.2137 & 2.34 & 0.21 & $2.98 \mathrm{E}-05$ & int \\
\hline rs12587187 & 93435452 & $A / G$ & 0.3063 & 0.2193 & 2.36 & 0.21 & $3.11 \mathrm{E}-05$ & int \\
\hline rs4905017 & 93438821 & $C / A$ & 0.3175 & 0.2357 & 2.46 & 0.22 & $3.62 \mathrm{E}-05$ & int \\
\hline rs72704295 & 93430316 & $\mathrm{~T} / \mathrm{C}$ & 0.3015 & 0.2136 & 2.28 & 0.2 & 4.10E-05 & int \\
\hline rs8022484 & 93430003 & $\mathrm{G} / \mathrm{A}$ & 0.3014 & 0.2137 & 2.28 & 0.2 & $4.33 \mathrm{E}-05$ & int \\
\hline rs2295392 & 93429060 & $A / G$ & 0.3023 & 0.2141 & 2.23 & 0.2 & $5.24 \mathrm{E}-05$ & int \\
\hline rs58887679 & 93528433 & $\mathrm{~T} / \mathrm{C}$ & 0.3228 & 0.2168 & 1.88 & 0.16 & $8.13 \mathrm{E}-05$ & int \\
\hline rs56159253 & 93528802 & $\mathrm{G} / \mathrm{T}$ & 0.3221 & 0.2167 & 1.87 & 0.16 & 8.99E-05 & int \\
\hline rs1612612 & 93497111 & $A / G$ & 0.3457 & 0.2487 & 1.96 & 0.17 & $9.91 \mathrm{E}-05$ & int \\
\hline rs55901898 & 93529066 & $A / G$ & 0.3219 & 0.2172 & 1.86 & 0.16 & 1.07E-04 & int \\
\hline rs10144329 & 93487652 & $\mathrm{C} / \mathrm{T}$ & 0.3825 & 0.288 & 1.96 & 0.18 & $1.24 \mathrm{E}-04$ & int \\
\hline rs1740598 & 93499081 & $\mathrm{~T} / \mathrm{C}$ & 0.3553 & 0.2585 & 1.92 & 0.17 & $1.33 \mathrm{E}-04$ & int \\
\hline rs10144603 & 93487894 & $\mathrm{C} / \mathrm{T}$ & 0.383 & 0.2902 & 1.97 & 0.18 & $1.34 \mathrm{E}-04$ & int \\
\hline rs56041593 & 93544162 & $\mathrm{C} / \mathrm{T}$ & 0.3154 & 0.227 & 2.02 & 0.19 & $1.49 \mathrm{E}-04$ & int \\
\hline rs12587868 & 93494030 & $A / G$ & 0.3731 & 0.278 & 1.9 & 0.17 & $1.64 \mathrm{E}-04$ & int \\
\hline rs117634531 & 93525019 & $\mathrm{~T} / \mathrm{C}$ & 0.3905 & 0.3006 & 1.92 & 0.18 & 2.27E-04 & int \\
\hline rs10147739 & 93490742 & $\mathrm{~T} / \mathrm{C}$ & 0.383 & 0.2882 & 1.86 & 0.17 & $2.28 \mathrm{E}-04$ & int \\
\hline rs55663734 & 93510695 & $\mathrm{G} / \mathrm{C}$ & 0.3787 & 0.2883 & 1.8 & 0.17 & 4.49E-04 & int \\
\hline rs1740693 & 93510644 & $\mathrm{G} / \mathrm{C}$ & 0.3785 & 0.2878 & 1.78 & 0.17 & $4.88 \mathrm{E}-04$ & int \\
\hline rs1740694 & 93510531 & $A / G$ & 0.382 & 0.2918 & 1.76 & 0.17 & 5.77E-04 & int \\
\hline rs1740594 & 93512947 & $C / G$ & 0.3963 & 0.3055 & 1.75 & 0.16 & $5.92 \mathrm{E}-04$ & int \\
\hline rs4905027 & 93467174 & $\mathrm{~T} / \mathrm{G}$ & 0.4137 & 0.4968 & 0.54 & 0.18 & $6.26 \mathrm{E}-04$ & int \\
\hline rs1740695 & 93498375 & $A / G$ & 0.3936 & 0.3015 & 1.73 & 0.16 & $6.41 \mathrm{E}-04$ & int \\
\hline rs1740599 & 93498230 & $\mathrm{C} / \mathrm{T}$ & 0.3935 & 0.3014 & 1.72 & 0.16 & $6.54 \mathrm{E}-04$ & int \\
\hline rs1740696 & 93498149 & $\mathrm{C} / \mathrm{T}$ & 0.3933 & 0.3014 & 1.72 & 0.16 & $6.68 \mathrm{E}-04$ & int \\
\hline
\end{tabular}


Table 3. Cont.

\begin{tabular}{|c|c|c|c|c|c|c|c|c|}
\hline SNP & Position & Allele & MAF in Cases & MAF in Controls & $O R$ & Standard Error & $P$-value & Type \\
\hline rs2236131 & 93540906 & $A / G$ & 0.3293 & 0.2322 & 1.66 & 0.15 & $7.20 \mathrm{E}-04$ & int \\
\hline rs3783903 & 93482323 & $\mathrm{G} / \mathrm{A}$ & 0.3496 & 0.2612 & 1.6 & 0.15 & $1.92 \mathrm{E}-03$ & int \\
\hline rs12589470 & 93426405 & $\mathrm{~A} / \mathrm{C}$ & 0.3163 & 0.2402 & 1.69 & 0.17 & $2.26 \mathrm{E}-03$ & int \\
\hline rs12437283 & 93412166 & $\mathrm{~T} / \mathrm{C}$ & 0.4074 & 0.4754 & 0.61 & 0.18 & 5.07E-03 & int \\
\hline rs1740689 & 93544174 & $\mathrm{G} / \mathrm{A}$ & 0.4192 & 0.3336 & 1.48 & 0.14 & $5.29 \mathrm{E}-03$ & int \\
\hline rs2749507 & 93528759 & $A / G$ & 0.5047 & 0.4257 & 1.45 & 0.14 & $9.45 \mathrm{E}-03$ & int \\
\hline rs72704291 & 93420199 & $\mathrm{G} / \mathrm{A}$ & 0.3387 & 0.2668 & 1.49 & 0.15 & $9.58 \mathrm{E}-03$ & int \\
\hline rs1740691 & 93529213 & $\mathrm{~A} / \mathrm{C}$ & 0.5033 & 0.4257 & 1.45 & 0.14 & $9.78 \mathrm{E}-03$ & int \\
\hline rs72704292 & 93423970 & $A / G$ & 0.3304 & 0.2576 & 1.48 & 0.15 & $9.80 \mathrm{E}-03$ & int \\
\hline rs2749509 & 93528114 & $A / G$ & 0.5046 & 0.4255 & 1.43 & 0.14 & $1.02 \mathrm{E}-02$ & int \\
\hline rs57933052 & 93416067 & $\mathrm{~T} / \mathrm{C}$ & 0.3414 & 0.2714 & 1.48 & 0.16 & $1.13 \mathrm{E}-02$ & int \\
\hline rs61100258 & 93414467 & $\mathrm{G} / \mathrm{A}$ & 0.3497 & 0.281 & 1.49 & 0.16 & $1.16 \mathrm{E}-02$ & int \\
\hline rs2749508 & 93528319 & $\mathrm{C} / \mathrm{T}$ & 0.5056 & 0.429 & 1.42 & 0.14 & $1.26 \mathrm{E}-02$ & int \\
\hline rs3783924 & 93413261 & $\mathrm{C} / \mathrm{T}$ & 0.3464 & 0.2789 & 1.48 & 0.16 & $1.30 \mathrm{E}-02$ & int \\
\hline rs184040115 & 93524881 & $\mathrm{C} / \mathrm{T}$ & 0.4607 & 0.3945 & 1.4 & 0.15 & $2.33 \mathrm{E}-02$ & int \\
\hline
\end{tabular}

Abbreviations: $O R$, odds ratio.

a Int us2k: upstream-variant-2KB sequence variant within $2 \mathrm{~KB} 5^{\prime}$ of gene.

${ }^{b}$ Int trp: triplex forming sequences.

doi:10.1371/journal.pone.0086145.t003

the cases and controls and found that the statistical differences were more significant. Four SNPs (rs4586354, rs3783903, rs2236131, and rs 1740689) had a high odds ratio index for NTDs (Table 2). MACH was used to impute the un-genotyped SNPs in ITPK1 locus, using the reference panel ASN data (1000 Genomes Integrated Phase 1). Association test was performed by using logistic regression. Results showed that 64 SNPs were statistically significant ( $P$-value from 5E-02 to $3.25 \mathrm{E}-08)$ and were in the noncoding areas, among which rs882023, rs10132322 and rs8013870 were located in the meaningful regions of the intron (Table 3). Four tag SNPs of ITPK1 gene were analyzed, and showed that a LD was observed between all loci in this study population using http://analysis2.bio-x.cn/myAnalysis.php. Compared with the wild-haplotype GGAG, the TAGA haplotype had a significantly higher risk of NTDs $(O R=1.64,95 \% C I[1.15-2.33], P=0.006)$ (Table 4, Figure 1).

It has been reported that the different polymorphisms may hold different degrees of significance for the various NTD phenotypes [19]. So we analyzed the association of the ITPK1 polymorphisms with NTD phenotypes (anencephaly, spina bifida). The subtypes were based on those devised by Cabaret et al [20]. The research found that in the spina bifida group, individuals with the heterozygosis genotype were at a significantly increased risk for NTDs, compared with the wide type genotype (Table 5). In our study, the subtypes of spina bifida mainly include Q05.0 cervical spina bifida with hydrocephalus $(3.75 \%)$, Q 05.1 thoracic spina bifida with hydrocephalus (30\%), Q05.2 lumbar spina bifida with hydrocephalus (43.75\%), Q05.3 sacral spina bifida with hydrocephalus $(3.75 \%)$, Q 05.4 unspecified spina bifida with hydrocephalus $(12.5 \%)$, spina bifida combined with meningomyelocele $(5 \%)$ and spinal bifida occulta $(1.25 \%)$. We analyzed the subtypes of anencephaly and found that both anencephaly and anencephaly combined spina bifida were not statistically significant (Table 6). However the subtypes of spina bifida were statistically significant in the Q05.1 and Q05.2 (Table 7). The number of samples in Q05.0 ( $\mathrm{n}=3)$; Q05.3 ( $\mathrm{n}=3)$; Q05.4 ( $\mathrm{n}=10)$; spina bifida combined with meningomyelocele $(\mathrm{n}=4)$ and spinal bifida occulta $(n=1)$ were too less and they were not statistically analyzed.

\section{Prediction Transcription Factor and Function Tests}

In this study, we predicted the binding capacity of the different genotypes of the four tag SNPs to potential transcription factor using the bioinformatics method and found that the AA genotype of the rs3783903 was located in the conserved sequence of approximate transcription factors AP-1, and there were not any other predicted transcription factor sites in the oligo of rs3783903. The other 3 sites were located in the non-conserved sequences of the transcription factor binding sites. Then we applied EMSA to detect that whether the rs3783903 polymorphism could change the binding ability of the sequence to the transcription factor AP-1.

The Wt-probe containing the AP-1 DNA-binding consensus site was incubated with the nuclear extracts from HeLa cell, shown in

Table 4. Haplotype of 4 SNPs rs4586354, rs3783903, rs2236131 and rs1740689 in ITPK1 gene and their relative risks for NTDs.

\begin{tabular}{lllllllll}
\hline Haplotype & rs4586354 & rs3783903 & rs2236131 & rs1740689 & Frequency & OR(95\% CI) & $P$ \\
\hline Wild-Haplotype & T & A & G & A & 0.5454 & 1 & 0.0063 \\
Mut-Haplotype & C & G & A & G & 0.1898 & $1.64(1.15,233)$ & 0.0063
\end{tabular}

Abbreviations: NTD, neural tube defect; OR, odds ratio; $95 \% \mathrm{Cl}, 95 \%$ confidence interval.

doi:10.1371/journal.pone.0086145.t004 


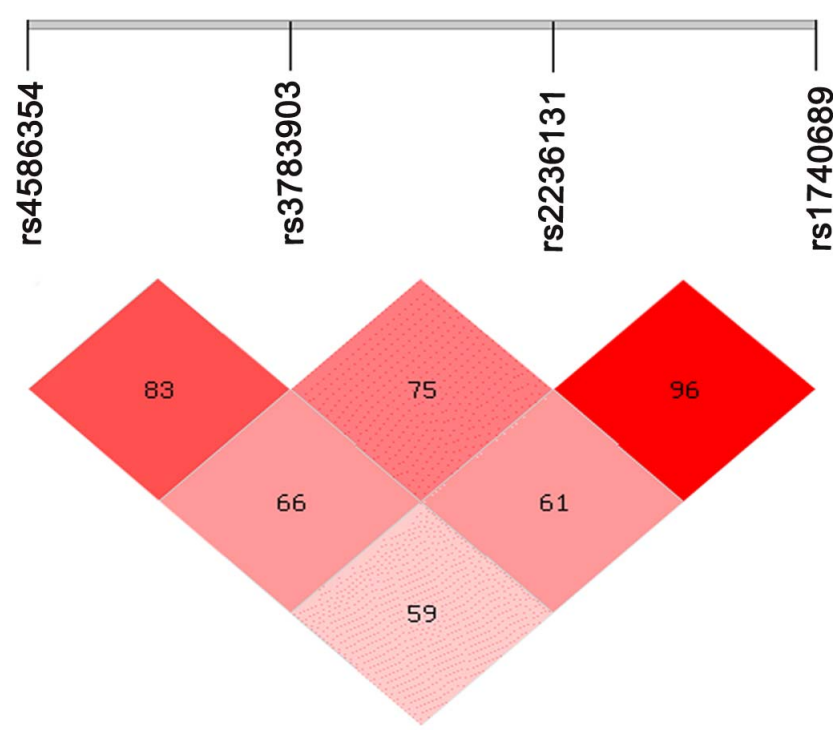

Figure 1. LD patterns of SNPs rs4586354, rs3783903, rs2236131 and rs1740689. The linkage patterns between the statistical difference four SNPs in all samples. The numbers in diamond represent the $100 \times D^{\prime}$ in the form of standard color scheme. The upper bar denotes the relative distance among the SNPs. The bright red box denotes $\mathrm{D}^{\prime}=1$ and $L O D \geq 2$; the pink box denotes $\mathrm{D}^{\prime}<1$ and $L O D \geq 2$. doi:10.1371/journal.pone.0086145.g001

Figure. 2. To be certain that AP-1 is truly binding, AP-1 was incubated with an anti-c-fos and anti-c-jun antibodies with a supershift. Results showed anti-c-fos and anti-c-jun antibodies abrogated the AP-1 biding. Besides, when the unlabeled mutant probes were added to the wild-type labeled probes and the mutant probes failed to compete with the wild-type probes for AP-1 binding. Results showed a different allelic binding capacity of AP-1 in the intron region of the ITPK1, which was affected by an $\mathrm{A} \rightarrow \mathrm{G}$ exchange. Results suggested that the polymorphism affect the transcription factor binding ability. Therefore, it might regulate the expression and transcription of the ITPK1 gene.

\section{The Concentration of the Maternal Plasma IP 6}

Table 8 showed that the plasma $\mathrm{IP}_{6}$ levels for the different genotypes between control and case were significant difference. The maternal plasma $\mathrm{IP}_{6}$ concentrations in the spina bifida subgroup were $7.1 \%$ lower than the control group (136.67 vs. 147.05 ngmL-1, $\mathrm{P}<0.05)$. Besides, compared with the other genotypes, mothers with the GG genotype had the lowest plasma $\mathrm{IP}_{6}$ levels, and the difference was significant $(P<0.05)$.

\section{The Difference of ITPK1 rs3783903 Expression in the 60 Healthy Women}

RT-PCR was performed to examine whether different mRNA expression of rs3783903 alleles was involved in SNP-induced levels of ITPK1 RNA (Figure. 3). The value was defined as the expression ratio of ITPK1 to GAPDH. The expression of ITPK1 was decreased significantly in mutant type of rs3783903 compared with wild type (GG: $\mathrm{AA}=0.59 ; P<0.05)$.

\section{Discussion}

The present study suggested that the polymorphism of ITPK1 might be a genetic risk factor for NTDs, which provides a clue for elucidating the mechanism of NTDs induced by ITPK1 polymorphism. The risk SNPs in ITPK1 gene might be an indicator of the susceptibility to NTDs during the prenatal examination and serve as an individualized strategy to prevent NTDs.

As a maternal nutrition factor, inositol plays a vital role in embryo development and especially in prevention of NTDs [21]. During embryo development, inositol can be produced as L-myoinositol-1-phosphate from D-glucose 6-phosphate [22], and it can be derived from maternal placenta which is the major source [23]. In the present study, we tested the concentration of maternal IP6

Table 5. SNPs genotypes frequencies of the 4 SNPs in the 2 subtype groups.

\begin{tabular}{|c|c|c|c|c|}
\hline SNP & Genotype & Controls (\%) & Anencephaly (\%) & Spina Bifida (\%) \\
\hline \multirow[t]{4}{*}{ rs4586354 } & $\pi$ & $164(54.1)$ & $52(53.1)$ & $29(39.7)$ \\
\hline & $\mathrm{CT}+\mathrm{CC}$ & $139(45.9)$ & $46(46.9)$ & $44(60.3)$ \\
\hline & $O R(95 \% C l)$ & 1 & $1.04(0.66,1.65)$ & $1.79(1.06,3.01)$ \\
\hline & $P^{a}$ & & 0.85 & 0.027 \\
\hline \multirow[t]{4}{*}{ rs3783903 } & $\mathrm{AA}$ & $165(52.2)$ & $48(47.5)$ & $26(32.5)$ \\
\hline & $A G+G G$ & $151(47.8)$ & $53(52.5)$ & $54(67.5)$ \\
\hline & OR $(95 \% C l)$ & 1 & $1.21(0.77,1.89)$ & $2.27(1.35,3.81)$ \\
\hline & $P^{a}$ & & 0.41 & 0.002 \\
\hline \multirow[t]{4}{*}{ rs2236131 } & GG & $181(58)$ & $47(47.5)$ & $31(40.3)$ \\
\hline & $A G+A A$ & $138(42.3)$ & $52(52.5)$ & $48(58.5)$ \\
\hline & $O R(95 \% C l)$ & 1 & $1.45(0.92,2.28)$ & $2.03(1.23,3.36)$ \\
\hline & $P^{\text {a }}$ & & 0.11 & 0.008 \\
\hline \multirow[t]{4}{*}{ rs1740689 } & AA & $139(44.3)$ & $34(27.3)$ & $21(27.3)$ \\
\hline & $A G+G G$ & $175(55.8)$ & $63(64.9)$ & $56(72.3)$ \\
\hline & $O R(95 \% C l)$ & 1 & $1.47(0.92,2.36)$ & $2.12(1.22,3.67)$ \\
\hline & $P^{a}$ & & 0.11 & 0.007 \\
\hline
\end{tabular}

Abbreviations: SNP, single-nucleotide polymorphism; $O R$, odds ratio; $C l$, confidence interval.

a $P$ values were calculated by $x^{2}$ test $2 \times 2$ contingency table for genotype distribution.

doi:10.1371/journal.pone.0086145.t005 
Table 6. SNPs genotypes frequencies of the 4 SNPs in the subtype of anencephaly.

\begin{tabular}{|c|c|c|c|c|c|}
\hline SNP & Genotype & Contol (\%) & Total Anencephaly (\%) & Anencephaly \& SB*(\%) & Only Anencephaly(\%) \\
\hline \multirow[t]{4}{*}{ rs4586354 } & $\pi$ & $164(54.1)$ & $52(53.1)$ & $33(52.4)$ & $12(52.2)$ \\
\hline & $\mathrm{CT}+\mathrm{CC}$ & $139(45.9)$ & $46(46.9)$ & $30(47.6)$ & $11(74.8)$ \\
\hline & $O R(95 \% \mathrm{Cl})$ & 1 & $1.04(0.66,1.65)$ & $1.3(0.75,2.2)$ & $1.02(0.46,2.5)$ \\
\hline & $P^{a}$ & & 0.85 & 0.34 & 0.85 \\
\hline \multirow[t]{4}{*}{ rs3783903 } & AA & $165(52.2)$ & $48(47.5)$ & $30(47.6)$ & $11(44)$ \\
\hline & $\mathrm{AG}+\mathrm{GG}$ & $151(47.8)$ & $53(52.5)$ & $33(52.4)$ & $14(56)$ \\
\hline & $O R(95 \% C l)$ & 1 & $1.21(0.77,1.89)$ & $1.2(0.7,2.1)$ & $1.4(0.6,3.5)$ \\
\hline & $P^{a}$ & & 0.41 & 0.5 & 0.4 \\
\hline \multirow[t]{4}{*}{ rs2236131 } & GG & $181(58)$ & $47(47.5)$ & $33(53.2)$ & $10(41.6)$ \\
\hline & $\mathrm{AG}+\mathrm{AA}$ & $138(42.3)$ & $52(52.5)$ & $29(46.8)$ & $14(58.4)$ \\
\hline & $O R(95 \% C l)$ & 1 & $1.45(0.92,2.28)$ & $1.15(0.67,1.9)$ & $1.8(0.8,4.2)$ \\
\hline & $P^{a}$ & & 0.11 & 0.6 & 0.15 \\
\hline \multirow[t]{4}{*}{ rs1740689 } & AA & $139(44.3)$ & $34(27.3)$ & $20(32.8)$ & $8(34.8)$ \\
\hline & $\mathrm{AG}+\mathrm{GG}$ & $175(55.8)$ & $63(64.9)$ & $41(67.2)$ & $15(65.2)$ \\
\hline & $O R(95 \% C l)$ & 1 & $1.47(0.92,2.36)$ & $1.63(0.9,2.9)$ & $1.49(0.6,3.6)$ \\
\hline & $P^{a}$ & & 0.11 & 0.1 & 0.37 \\
\hline
\end{tabular}

*Spina Bifida.

Abbreviations: SNP, single-nucleotide polymorphism; $O R$, odds ratio; $\mathrm{Cl}$, confidence interval.

${ }^{\mathrm{a}} P$ values were calculated by $x^{2}$ test $2 \times 2$ contingency table for genotype distribution.

doi:10.1371/journal.pone.0086145.t006

level to determine the relationship between various genotypes of rs3783903. Results showed that the plasma $\mathrm{IP}_{6}$ concentrations in spina bifida group were lower than that in control $(P<0.05) . \mathrm{IP}_{6}$ levels in the GG sub-genotype of rs3783903 was significantly lower than that in groups of other genotypes $(P<0.05)$. The ITPK1 is a key and the rate-limiting enzyme in the synthesis of $\mathrm{IP}_{4}, \mathrm{IP}_{5}$ and
$\mathrm{IP}_{6}$ in mammalian cells [24]. Deficiency of the key enzymes in the inositol metabolic pathways may decrease the inositol levels in maternal and embryonic cell, leading to the signal transduction disorder and inhibiting the cell movement, proliferation and differentiation. SNPs in the ITPK1 dynamically regulated the metabolisms of inositol. It is supposed that the decreased maternal

Table 7. SNPs genotypes frequencies of the 4 SNPs in the subtype of spina bifida.

\begin{tabular}{|c|c|c|c|c|c|}
\hline SNP & Genotype & Controls (\%) & Spina Bifida (\%) & $\begin{array}{l}\text { Thoracic spina bifida with } \\
\text { hydrocephalus (\%) }\end{array}$ & $\begin{array}{l}\text { Lumbar spina bifida with } \\
\text { hydrocephalus (\%) }\end{array}$ \\
\hline \multirow[t]{4}{*}{ rs4586354 } & $\pi$ & $164(54.1)$ & $29(39.7)$ & $7(30.4)$ & $13(37)$ \\
\hline & $\mathrm{CT}+\mathrm{CC}$ & $139(45.9)$ & $44(60.3)$ & 16 (69.6) & $22(63)$ \\
\hline & $O R(95 \% C l)$ & 1 & $1.79(1.06,3.01)$ & $2.6(1.1,6.7)$ & $2(0.97,4.1)$ \\
\hline & $P^{a}$ & & 0.027 & 0.03 & 0.042 \\
\hline \multirow[t]{4}{*}{ rs3783903 } & $\mathrm{AA}$ & $165(52.2)$ & $26(32.5)$ & $10(41.6)$ & $10(28.6)$ \\
\hline & $A G+G G$ & $151(47.8)$ & 54 (67.5) & 14 (58.4) & 25 (71.4) \\
\hline & $O R(95 \% C l)$ & 1 & $2.27(1.35,3.81)$ & $1.5(0.6,3.5)$ & $2.7(1.2,5.8)$ \\
\hline & $P^{a}$ & & 0.002 & 0.2 & 0.006 \\
\hline \multirow[t]{4}{*}{ rs2236131 } & GG & $181(58)$ & $31(40.3)$ & $7(31.8)$ & $12(34.3)$ \\
\hline & $A G+A A$ & $138(42.3)$ & $48(58.5)$ & $15(68.2)$ & $23(65.7)$ \\
\hline & $O R(95 \% C l)$ & 1 & $2.03(1.23,3.36)$ & $2.8(1.14,7.0)$ & $2.5(1.26,5.2)$ \\
\hline & $P^{a}$ & & 0.008 & 0.027 & 0.009 \\
\hline \multirow[t]{4}{*}{ rs1740689 } & $\mathrm{AA}$ & $139(44.3)$ & $21(27.3)$ & $6(25)$ & 9 (25.6) \\
\hline & $A G+G G$ & $175(55.8)$ & $56(72.3)$ & $18(75)$ & $26(74.4)$ \\
\hline & $O R(95 \% C l)$ & 1 & $2.12(1.22,3.67)$ & $2.3(0.9,6.1)$ & $2.3(1.0,5.1)$ \\
\hline & $P^{a}$ & & 0.007 & 0.05 & 0.04 \\
\hline
\end{tabular}

Abbreviations: SNP, single-nucleotide polymorphism; $O R$, odds ratio; $\mathrm{Cl}$, confidence interval.

a $P$ values were calculated by $x^{2}$ test $2 \times 2$ contingency table for genotype distribution.

doi:10.1371/journal.pone.0086145.t007 
Ab Shift banding

\section{AP-1}
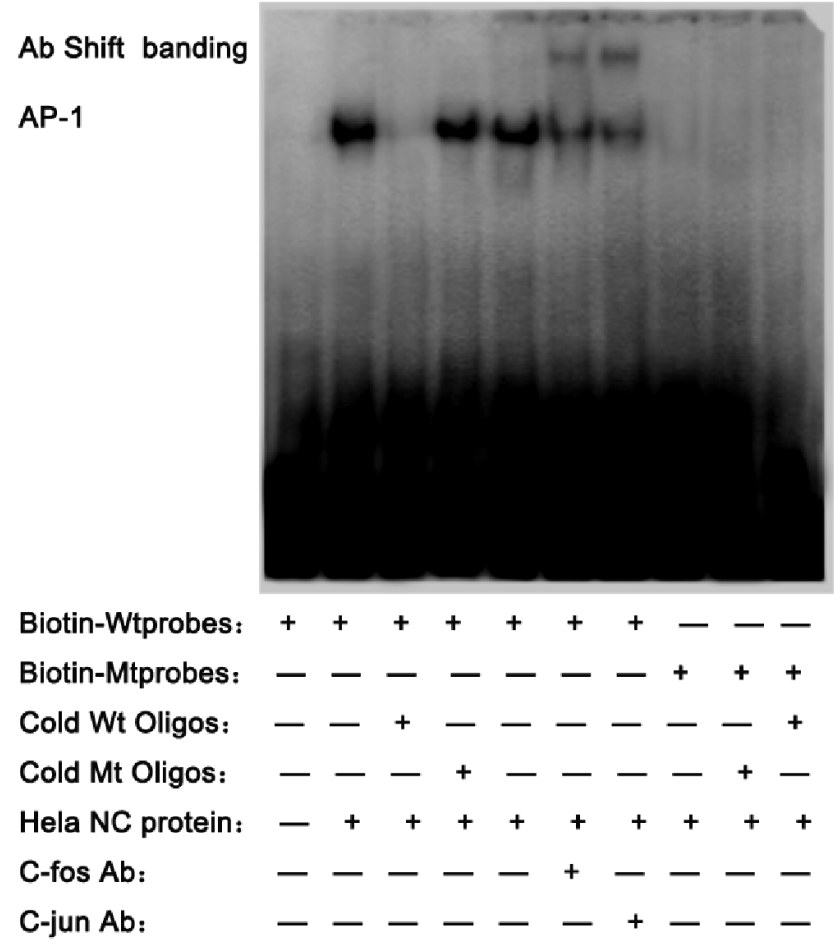

Figure 2. The Comparison of Wt-Oligos and Mut-Oligos in the ability of transcription factors combination. Line 1, the blank control without the nuclear extracts from HeLa cell; Line 2, the Biotin Wt-probe were incubated with the nuclear extracts from HeLa cell; Line 3-4, competition was also performed using Cold Wt Oligos and Cold Mt Oligos; Line 5, the negative control of supershift line, incubated with IgG; Line 6-7, performed with antibodies specific for c-fos, c-jun; Line $8-10$, the Mut-probe were showed for the control. These results showed a different allelic binding capacity of AP-1 in rs3783903 of the ITPK1, which is affected by an $A \rightarrow G$ exchange.

doi:10.1371/journal.pone.0086145.g002

inositol levels might affect the placental transfer of inositol, and further affect the development of the fetus.

Our study found that there were no significant differences in general characteristics between groups except that the gestational week in controls was lower than that in cases due to the reason that some pregnant women aborted for non-medical reasons during early pregnancy. So the population we selected was representative. In the study, we found that four tag SNPs in the ITPK1 gene in NTD-affected pregnancies were significantly associated with NTDs. In further stratified analysis we found that these SNPs were also significant in the spina bifida group $(P<0.05, O R>1)$.

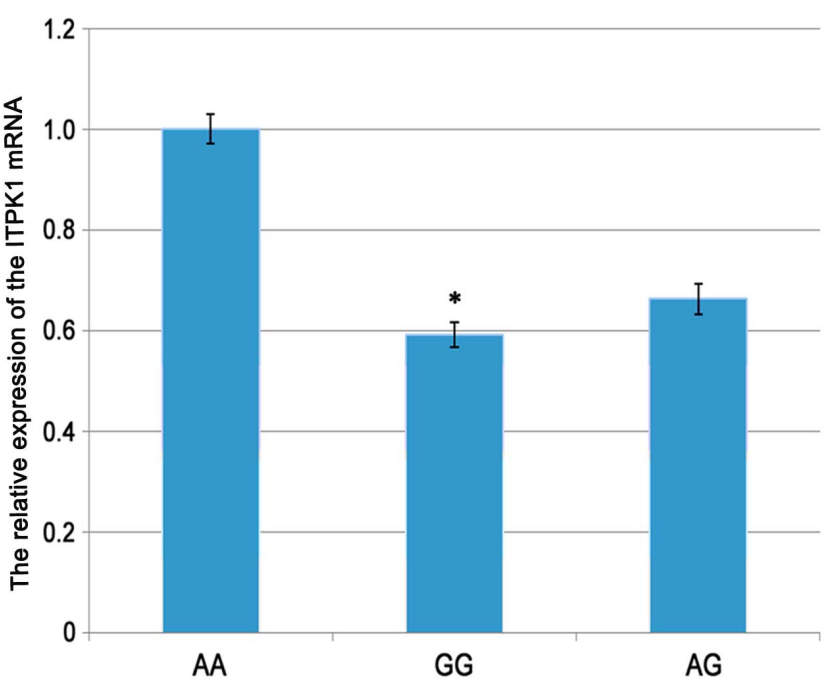

Figure 3. The expression of ITPK1 gene using quantitative realtime PCR $(* \mathbf{P}<\mathbf{0 . 0 5})$. The expression of ITPK1 was decreased significantly in mutant type of rs3783903 compared with wild type (GG: $A A=0.59 ; P<0.05$ ). doi:10.1371/journal.pone.0086145.g003

Neural tube closure initiated from the tips of the neural ridges which is termed Closure 1. The failure of neural tube in Closure 1 between the midbrain and spine causes craniorachischisis. A partial failure in Closure 1 in the lumbosacral or thoracic region causes the common human birth defect, spina bifida [25]. ITPK1 is expressed in the neural epithelium and neural crest derivatives during the developing of embryo. The SNPs, induced defects of the key enzymes (ITPK1) in inositol metabolic pathway might reduce $\mathrm{IP}_{6}$ levels in maternal and embryonic cells, resulting in disorders in the dynamic cellular behaviors in Closure 1 including cell rearrangement, cell proliferation and cell apoptosis. These events would further induce spina bifida. Different NTD phenotypes are related with different dysfunctional events and susceptibility in diverse closure sites during embryonic stages [26]. It is suggested that spina bifida is more susceptible to the polymorphism of ITPK1 in NTD-affected pregnancies.

NTDs is a complex etiology involving both environmental and genetic factors [27]. The multi-SNPs will affect the genetically susceptibility to diseases. A difference between the haplotypes of polymorphisms can represent the combined effect of the polymorphisms or it can represent the effect of a polymorphism to which the haplotype is in LD [28]. In present study, four different tag SNPs of ITPK1 gene (rs4586354, rs1740689, rs2236131 and rs3783903) were analyzed and we found that the

Table 8. $\mathrm{IP}_{6}$ levels in plasma samples from maternal $\mathrm{rs} 3783903$ (values expressed in $\mathrm{ng} \mathrm{mL}^{-1}$ ).

\begin{tabular}{|c|c|c|c|c|c|}
\hline & Control (Mean $\left.\pm S D, n^{a}\right)$ & Case $\left(\right.$ Mean $\left.\pm S D, n^{a}\right)$ & $P^{\mathbf{b}}$ & Total $^{c}$ & $P^{c}$ \\
\hline AA & $150.95 \pm 20.4(20)$ & $140.2 \pm 17.98(20)$ & 0.041 & $145.58 \pm 19.85(40)$ & \\
\hline AG & $149.05 \pm 20.44(20)$ & $138.4 \pm 18.8(20)$ & 0.049 & $143.73 \pm 20.11(40)$ & 0.634 \\
\hline GG & $141.15 \pm 18.91(20)$ & $131.4 \pm 14.79(20)$ & 0.033 & $136.28 \pm 17.4(40)$ & 0.01 \\
\hline Total & $147.05 \pm 19.94(60)$ & $136.67 \pm 17.29(60)$ & 0.001 & & \\
\hline
\end{tabular}

${ }^{a} \mathrm{n}$ refered to the number of subjects.

${ }^{\mathrm{b}}$ Student's test was used to calculate the $P$ values (control VS case).

CAnalysis of variance was used to calculate the $P$ values and the GG genotype is significant different than other genotypes $(P=0.01)$.

doi:10.1371/journal.pone.0086145.t008 
haplotype TAGA increased a significant risk of NTDs $(O R=1.64$, $95 \%$ CI [1.15-2.33], $P=0.006)$. The result suggested that GGAG haplotype of ITPK1 also played a role in modulating the susceptibility to NTDs and might become a genetically susceptible index to provide the experimental evidence in screening the high risk population. The four positive tag SNPs are located in the intronic regions. MACH was used to impute the un-genotyped SNPs in ITPK1 locus by use of the reference panel ASN data (1000 Genomes Integrated Phase 1). Results showed that the rs882023 $(P=1.59 \mathrm{E}-04), \quad \mathrm{rs} 10132322 \quad(P=2.52 \mathrm{E}-04)$ and $\mathrm{rs} 8013870$ $(P=3.86 \mathrm{E}-02)$ were in the meaningful region of the intron. Polymorphisms in non-coding regions can affect the expression of a genes [29]. These SNPs may involve in the process of intron splicing and mRNA transcription and result in the aberrant expression of ITPK1. In addition, we predicted the binding capacity of the different genotypes of the positive tag SNPs to the potential transcription factors using the bioinformatics method. Results revealed that that AA genotype of rs3783903 was located in the conserved sequence of AP-1 with more significance than other SNPs. Many reports showed that the genetic variations in introns have impacts on modulations of gene regulation, transcript processing or chromosomal rearrangements [30,31]. Reardon HT et al reported that six SNPs in the first intron of the FADS2 gene were associated with the expression of FADS1 [32]. Park TJ et al found that one common polymorphism in Intron 11, rs3816491, was most intensively associated with susceptibility to aspirinAERD [33]. The study from Khan Sikandar G also showed that mutations in Intron 3 of the DNA repair gene affected pre-mRNA splicing in association with many skin cancers [34]. Kubota Tomoya et al found that a patient with myotonia was caused by a deletion/insertion located in Intron 21 of SCN4A, which is an ATAC type II intron, and the first intronic mutation in a voltagegatedion channel gene showing a gain-of-function defect [35]. The ITPK1 gene contains 11 exons, 10 introns (up to 179405 bases) and the alternative splicing, suggests an indispensable role for exonic splicing enhancer sequences in intron. The rs3783903 is located in the conserved sequence of AP-1 distinguished from the other 3 sites. The rs3783903 SNP is associated with the expression levels of ITPK1. EMSA assays showed that the nucleo-protein complex was more effectively binded with the AP-1 of " $\mathrm{A}$ " allele rather than "G" allele. The rs3783903 SNP acted as a genetically modified factor and regulated alternative splicing in intron. The mRNA levels of ITPK1 in homozygously mutated NTDs pregnancies were significantly lower than wild type in the healthy pregnant women determined by RT-PCR $(P<0.05)$. The AP-1 combined with the mut-genotype might affect the promoter/ enhancer activity that regulates the expression of ITPK1 gene.

\section{References}

1. Au KS, Ashley-Koch A, Northrup H (2010) Epidemiologic and genetic aspects of spina bifida and other neural tube defects. Dev Disabil Res Rev 16: 6-15.

2. Groenen PM, Peer PG, Wevers RA, Swinkels DW, Franke B, et al (2003) Maternal myo-inositol, glucose, and zinc status is associated with the risk of offspring with spina bifida. Am J Obstet Gynecol 189: 1713-1719.

3. Greene ND, Copp AJ (1997) Inositol prevents folate-resistant neural tube defects in the mouse. Nat Med 3: 60-66.

4. Reece EA, Khandelwal M, Wu YK, Borenstein M (1997) Dietary intake of myoinositol and neural tube defects in offspring of diabetic rats. Am J Obstet Gynecol 176: 536-539.

5. De Grazia S, Carlomagno G, Unfer V, Cavalli P (2012) Myo-inositol soft gel capsules may prevent the risk of coffee-induced neural tube defects. Expert Opin Drug Deliv 9: 1033-1039.

6. Wilson MP, Majerus PW (1996) Isolation of inositol 1,3,4-trisphosphate 5/6kinase, cDNA cloning and expression of the recombinant enzyme. J Biol Chem 271: 11904-11910
Moreover, these might also regulate the splicing of ITPK1 and influence the inositol metabolism pathway.

To our best knowledge, the present study is the first one to report a tag SNPs based selection of ITPK1 gene polymorphisms with NTDs risk in the Lvliang mountain area of Shanxi Province in Northern China. The replication of association findings using independently collected samples is very important for the assessment of a positive finding and its generality. Besides, it is essential to provide convincing statistical evidence for association, and to rule out associations due to biases. Therefore, it is beneficial to establish the credibility of a genotype - phenotype association which is derived from candidate-gene or genome-wide association studies [36]. However, replication of our study was challenging because a suitable study would have included the same phenotype, under similar environmental background and the matched age, gravidity, parity, educational level, so a relatively larger population based cohorts would be needed to have sufficient power for replication. In our future works, we will continue to collect specimens to further evaluate data that are generated. Furthermore, our findings need to be validated in different ethnicities with a gene expression functional assay.

\section{Conclusions}

These results suggested that the maternal rs3783903 of ITPK1 might be associated with spina bifida, and the allele $G$ of rs3783903 in ITPK1 gene might affect the AP-1 binding and lead to the decrease of maternal plasma $\mathrm{IP}_{6}$ concentration, which might play roles in the pathogenesis of spina bifida in this Chinese population.

\section{Supporting Information}

Table S1 The positive tag SNPs genotypes and allele frequencies in NTDs and controls. The table showed that the four tag SNPs were significantly different between cases ("anencephaly", "spina bifida" and "encephalocele") and controls.

(DOC)

\section{Acknowledgments}

Our group is greatly indebted to the participants for taking part in the study, to the healthcare workers for collecting the samples.

\section{Author Contributions}

Conceived and designed the experiments: BN TZ ZG JHW. Performed the experiments: ZG JHW JG FW XWW. Analyzed the data: GNL QX. Contributed reagents/materials/analysis tools: $\mathrm{XH}$. Wrote the paper: ZG JHW.

7. Chang SC, Miller AL, Feng Y, Wente SR, Majerus PW (2002) The human homolog of the rat inositol phosphate multikinase is an inositol 1,3,4,6tetrakisphosphate 5-kinase. J Biol Chem 277: 43836-43843.

8. Verbsky JW, Wilson MP, Kisseleva MV, Majerus PW, Wente SR (2002) The synthesis of inositol hexakisphosphate: Characterization of human inositol 1,3,4,5,6-pentakisphos-phate 2-kinase. J Biol Chem 277: 31857-31862.

9. Verbsky JW, Chang SC, Wilson MP, Mochizuki Y, Majerus PW (2005) The pathway for the production of inositol hexakisphosphate in human cells. J Biol Chem 280: 1911-1920.

10. Wilson MP, Hugge C, Bielinska M, Nicholas P, Majerus PW, et al. (2009) Neural tube defects in mice with reduced levels of inositol 1,3,4-trisphosphate 5/ 6-kinase. Proc Natl Acad Sci U S A 106: 9831-9835.

11. Gu X, Lin L, Zheng X, Zhang T, Song X, et al. (2007) High prevalence of NTDs in Shanxi Province: a combined epidemiological approach. Birth Defects Res A Clin Mol Teratol 79: 702-707.

12. Natarajan R, Turnbull BW, Slate EH, Clark LC (1996) A computer program for sample size and power calculations in the design of multi-arm and factorial 
clinical trials with survival time endpoints. Comput Methods Programs Biomed 49: $137-147$.

13. Barrett JC, Fry B, Maller J, Daly MJ (2005) Haploview: analysis and visualization of $\mathrm{LD}$ and haplotype maps. Bioinformatics 21: 263-265.

14. Smith AV (2008) Browsing HapMap Data Using the Genome Browser. CSH Protoc 2008: pdb prot5023.

15. Tur F, Tur E, Lentheric I, Mendoza P, Encabo M, et al. (2013) Validation of an LC-MS bioanalytical method for quantification of phytate levels in rat, dog and human plasma. J Chromatogr B Analyt Technol Biomed Life Sci 928: 146-154.

16. Sole X, Guino E, Valls J, Iniesta R, Moreno V (2006) SNPStats: a web tool for the analysis of association studies. Bioinformatics 22: 1928-1929.

17. Sanna S, Jackson AU, Nagaraja R, Willer CJ, Chen WM, et al. (2008) Common variants in the GDF5-UQCG region are associated with variation in human height. Nat Genet 40: 198-203.

18. Willer CJ, Sanna S, Jackson AU, Scuteri A, Bonnycastle LL, et al. (2008) Newly identified loci that influence lipid concentrations and risk of coronary artery disease. Nat Genet 40: 161-169.

19. Relton CL, Wilding CS, Jonas PA, Lynch SA, Tawn EJ, et al. (2003) Genetic susceptibility to neural tube defect pregnancy varies with offspring phenotype. Clin Genet 64: 424-428.

20. Cabaret AS, Loget P, Loeuillet L, Odent S, Poulain P (2007) Embryology of neural tube defects: information provided by associated malformations. Prenat Diagn 27: 738-742.

21. Uldry M, Ibberson M, Horisberger JD, Chatton JY, Riederer BM, et al. (2001) Identification of a mammalian $\mathrm{H}(+)$-myo-inositol symporter expressed predominantly in the brain. EMBO J 20: 4467-4477.

22. Majumder AL, Johnson MD, Henry SA (1997) 1L-myo-inositol-1-phosphate synthase. Biochim Biophys Acta 1348: 245-256.

23. Scioscia M, Siwetz M, Fascilla F, Huppertz B (2012) Placental expression of Dchiro-inositol phosphoglycans in preeclampsia. Placenta 33: 882-884.

24. Theibert AB, Estevez VA, Ferris CD, Danoff SK, Barrow RK, et al. (1991) Inositol 1,3,4,5-tetrakisphosphate and inositol hexakisphosphate receptor proteins: isolation and characterization from rat brain. Proc Natl Acad Sci U S A 88: 3165-3169.
25. Yamaguchi Y, Miura M (2012) How to form and close the brain: insight into the mechanism of cranial neural tube closure in mammals. Cell Mol Life Sci Dec 15. [Epub ahead of print].

26. Ahmad FU, Mahapatra AK (2009) Neural tube defects at separate sites: further evidence in support of multi-site closure of the neural tube in humans. Surg Neurol 71: 353-356.

27. Wald NJ, Bower C (1994) Folic acid, pernicious anaemia, and prevention of neural tube defects. Lancet 343: 307.

28. Crawford DC, Nickerson DA (2005) Definition and clinical importance of haplotypes. Annu Rev Med 56: 303-320.

29. Knight JC (2005) Regulatory polymorphisms underlying complex disease traits. J Mol Med (Berl) 83: 97-109.

30. Weickert CS, Miranda-Angulo AL, Wong J, Perlman WR, Ward SE, et al. (2008) Variants in the estrogen receptor alpha gene and its mRNA contribute to risk for schizophrenia. Hum Mol Genet 17: 2293-2309.

31. Athanasiu L, Mattingsdal M, Melle I, Inderhaug E, Lien T, et al. (2011) Intron 12 in NTRK3 is associated with bipolar disorder. Psychiatry Res 185: 358-362.

32. Reardon HT, Zhang J, Kothapalli KS, Kim AJ, Park WJ, et al. (2012) Insertiondeletions in a FADS2 intron 1 conserved regulatory locus control expression of fatty acid desaturases 1 and 2 and modulate response to simvastatin. Prostaglandins Leukot Essent Fatty Acids 87: 25-33.

33. Park TJ, Kim JH, Bae JS, Park BL, Cheong HS, et al. (2012) Potential Association Between ANXA4 Polymorphisms and Aspirin-exacerbated Respiratory Disease. Diagn Mol Pathol 27.

34. Khan SG, Yamanegi K, Zheng ZM, Boyle J, Imoto K, et al. (2010) XPC branch-point sequence mutations disrupt U2 snRNP binding, resulting in abnormal pre-mRNA splicing in xeroderma pigmentosum patients. Hum Mutat 31: $167-175$.

35. Kubota T, Roca X, Kimura T, Kokunai Y, Nishino I, et al. (2011) A mutation in a rare type of intron in a sodium-channel gene results in aberrant splicing and causes myotonia. Hum Mutat 32: 773-782.

36. Chanock SJ, Manolio T, Boehnke M, Boerwinkle E, Hunter DJ, et al. (2007) Replicating genotype-phenotype associations. Nature 447: 655-660. 